\title{
Genetic estimates and trend analysis of some growth parameters of cashew (Anacardium occidentale L.) as influenced by nine nutrient combinations
}

\author{
B. D. Adewale ${ }^{1 *}$, O. S. Ibiremo ${ }^{2}$, N. C. Odoh ${ }^{3}$ and E. A. Adeyemi ${ }^{4}$ \\ ${ }^{1}$ Crop Improvement Division, Cocoa Research Institute of Nigeria, PMB 5244, Ibadan, Oyo State, Nigeria. \\ ${ }^{2}$ Soils and Plant Nutrition Division, Cocoa Research Institute of Nigeria, PMB 5244, Ibadan, Oyo State, Nigeria. \\ ${ }^{3}$ Department of Soil Science, University of Abuja, PMB 117, Abuja, Nigeria. \\ ${ }^{4}$ Agronomy Department, Cocoa Research Institute of Nigeria, PMB 5244, Ibadan, Oyo State, Nigeria.
}

Accepted 2 January, 2013

\begin{abstract}
Good seedling establishment has a positive impact on the productive capacity of tree crops. This study investigated the optimum combination of phosphorus and organic fertilizer (OF) for the growth of cashew seedling at the pre-flowering stage. Two cashew accessions of the same nut size category from two geographical sources (Ochaja and Oro, Kogi State of Nigeria) were evaluated to assess their responses to three types of phosphate fertilizer and three levels of OF. The eighteen treatment combinations were laid out in a randomized complete block design of three replicates. Two years monitoring of the growth of the cashew accessions resulted in significant $(P \leq 0.05)$ genotypic variation for most of the traits at quarterly intervals of measurement. Significant $(P \leq 0.05)$ variation existed among the three levels of OF at different stages of plant height, stem diameter and leaf area. Broad sense heritability was not consistent across the six quarters of the three growth parameters. It ranged from $0.16 \%$ (SDQ5) to $95.6 \%$ (HTQ1). The trend of growth of the stem diameter from quarter 1 to 6 was linear for the two accessions. However, the response of the same trait to the three levels of OF was negatively quadratic. The first two initial years of cashew development on the field falls within the actively growing period of the crop. This justifies the linear behaviour of the three quantitative growth parameters investigated, application of OF at 2.5 tonnes/ha could be optimum for young cashew.
\end{abstract}

Key words: Cashew, growth, accessions, trend analysis.

\section{INTRODUCTION}

The increase in the global production of cashew is due to the realization of the health and economic value of the crop. The ever increasing global demand for cashew nuts as remarked by Adavi (2008) is because cashew kernels provide a predominantly unsaturated fat. The relative abundance of monounsaturated fatty acids in cashew nut is an advantage, since mono-unsaturated are now

${ }^{\star}$ Corresponding author. E-mail: d.adewale@gmail.com. Tel: +234-803-9228-085. believed to be as efficient as polyunsaturated in lowering serum cholesterol. In addition to the less health risk, protein in cashew is abundant $(>20 \%)$ and of a high quality probably more than in meat or fish (Soman, 1997), cited in Adavi (2008). The soluble sugar in the kernel is almost as low as 1\%; hence, cashew nut consumers are therefore privileged to get a sweet taste without having to worry about excess calories (SasiVarma, 2002).

Africa shares very low percentage of the world production of cashew; low yield per tree accounts for this. Most of the genotypes in Africa have very low productive capacity. Advances for improvement of African cashew 
are still slow. Phillip and Unni (1984) reported that cashew hosts high genotypic and phenotypic variability. Moreover, the out-breeding nature of the crop (Aliyu, 2005) may have been facilitating continual evolution of additional genetic resources in many agro-ecologies of Africa. Therefore, the poor stride in cashew improvement in Africa could be blamed on poor assessment and underutilization of available genetic resources of the crop. However, progress in the improvement of this crop species through conventional breeding methods has been hampered by long gestation period needed to generate genetic materials with better performances.

It is surprising to note that cashew is largely considered as a hardy species. Ordinarily, species thus classified do not receive proper cultural and managerial attention. For instance, until recent times, cashew was considered as a waste land crop, whose productivity is unaffected with or without improvement on its immediate environment. That cashew flourishes in soils where most other crops fail, Ohler (1979), does not imply that the crop does not need nutritional assistance for enhanced productivity. Cashew responds well to fertilizer application, especially during the vegetative growing period (Hammed et al., 2011). The response of cashew trees to mineral nutrients application in most cases are significantly dependent on plant age, the genotype, conditions of cultivation (soil and climate), other management schedules etc. (OpokuAmeyaw and Appiah, 2000; Ibiremo et al., 2012).

Most of the earlier works did ascertain that cause and effect interaction exists between cashew and mineral nutrient application. However, information on the trend of response and genetic indices of the growth parameters at different developmental stages may have not been attempted. Therefore, the objectives of this study were: to identify variability among cashew accessions to varied nutrient combinations for growth parameters, identify the pattern of trend in their responses and understand the genetic potentials of the cashew accessions for three growth parameters.

\section{MATERIALS AND METHODS}

The variability in the pattern and trend of response of growth of cashew genotypes to varied nutrient combinations was studied in 2007. Two accessions of cashew of the medium nut-size class were obtained from farmer's field at Ochaja and Oro in Kogi State of Nigeria; and were coded as: Kas_Oc and Kas_Or respectively. This study was carried out at the Cocoa Research Institute of Nigeria, Ibadan, Nigeria. The accessions were evaluated under nine nutritional treatment combinations involving three levels/types of Phosphorus application ( 0 and $30 \mathrm{~kg} \mathrm{P}_{2} \mathrm{O}_{5} /$ ha of Sokoto Rock Phosphate (SRP) and single super phosphate (SSP)) and three levels $(0,2.5$ and 5 tons/ha) of Organic fertilizer (OF) (cocoa pod husk).

The factorial experiment was laid out in Randomized Complete Block (RCB) design of three replications. Planting was done in July, 2007 from seeds at a spacing of 7 by $9 \mathrm{~m}$. The plant population per treatment per plot was ten. The phosphate and the organic fertilizers were applied in ring around individual plant at the third and fourth month respectively after crop establishment. The experiment was monitored for two years after field establishment. Data were taken on plant height, stem diameter and leave area at the intervals of four months for two years.

The data were subjected to analysis of variance (ANOVA) using PROC GLM in SAS (version 9.2; SAS Institute Inc., 2007) to obtain the variances for the main and interactions effects. Broad sense heritability, phenotypic coefficient of variation (PCV) and genotypic coefficient of variation (GCV) were estimated from the variance components following the approach of Singh and Chaudhary (1985). ANOVA was further conducted in which the six growth intervals were treated (by transpose) as a main effect along with organic fertilizer and phosphate levels to identify significant interaction between the factors.

Only stem diameter had a significant interaction ( $P \leq 0.05)$ between growth intervals and organic fertilizer. Hence, orthogonal polynomial procedure in trend analysis was done to unravel the trend of response of the trait for the two accessions according to Gomez and Gomez (1984). Graphical plots were made from Microsoft Excel to describe the trend of the responses of the stem diameter of the two accessions to the periodic intervals of growth measurement and organic fertilizer.

\section{RESULTS}

There existed significant variation $(P \leq 0.05)$ between the two cashew accessions with respect to plant height for all the six intervals of measurement except Q4 (Table 1). OF as a treatment, produced significant variation $(P \leq 0.05)$ in plant height in quarters 3,4 and 6 . The leaf area of the cashew accessions differed significantly $(P \leq 0.05)$ in quarters 1, 4, 5 and 6 (Table 1). OF only produced significant $(P \leq 0.001)$ differentiation in leaf area in quarter 5 . Moreover, the interaction between accession and phosphate fertilizer produced significant $(P \leq 0.05)$ variation in leaf area in quarter 4 , while the only second order interaction $\left(G^{*}{ }^{*} \mathrm{OF}{ }^{\star} \mathrm{PF}\right)$ produced significant $(\mathrm{P} \leq$ 0.05 ) variation for leaf area in quarters 2,3 and 5 (Table 1). The stem diameter of the two cashew accessions differed significantly $(P \leq 0.05)$ in quarters 2,3 and 6 . The other main effect with significant $(P \leq 0.05)$ variation for stem diameter in quarters 3 and 4 was OF. Gen x OF interaction significantly $(P \leq 0.05)$ differentiated the stem diameter in quarter 4 (Table 1). Absence of phosphate or its presence as either SSP or SRP did not produce significant variation in any of the three growth parameters (Table 1).

In Table 2, there was significant $(P \leq 0.001)$ response of each of the six quarterly intervals and the three levels of organic fertilizer on the development of the two cashew accessions (Kas_Oc and Kas_Or) for the three traits. Also significant $(\bar{P} \leq 0.05)$ differences existed among the means of the two accessions (Kas_Oc and Kas_Or) for plant height, stem diameter and leaf area with respect to the quarterly intervals. Similarly, significant $(P \leq 0.05)$ differences also occurred for plant height, stem diameter and leaf area with respect to the three levels of OF in Kas_Or only (Table 2). There were significant $(P \leq 0.05)$ additions to plant height, leaf area and stem diameter at 
Table 1. Summary of the analysis of variance for three growth parameters measured at six quarterly Intervals.

\begin{tabular}{|c|c|c|c|c|c|c|c|}
\hline \multirow{2}{*}{ Source } & \multirow{2}{*}{ DF } & \multicolumn{6}{|c|}{ Mean squares } \\
\hline & & HTQ1 & HTQ2 & HTQ3 & HTQ4 & HTQ5 & HTQ6 \\
\hline Gen & 1 & $2123.74^{\star \star \star}$ & $7952.97^{\star \star \star}$ & $9138.36^{\star \star \star}$ & 199.38 & $21869.23^{*}$ & $16757.70^{\star *}$ \\
\hline OF & 2 & 12.76 & 96.26 & $2352.85^{\star *}$ & $3479.06^{*}$ & 867.26 & $6364.31^{*}$ \\
\hline PF & 2 & 7.62 & 24.97 & 189.25 & 302.35 & 9864.72 & 861.78 \\
\hline Gen*OF & 2 & 10.09 & 77.38 & 462.60 & 2086.84 & 5544.59 & 3762.09 \\
\hline Gen*PF & 2 & 2.89 & 6.80 & 81.21 & 452.67 & 6344.78 & 370.87 \\
\hline OF*PF & 4 & 2.56 & 111.48 & 711.83 & 778.49 & 5287.27 & 956.59 \\
\hline \multirow[t]{2}{*}{ Gen*OF*PF } & 4 & 38.34 & 164.99 & 845.25 & 583.85 & 4210.11 & 831.18 \\
\hline & & LAQ1 & LAQ2 & LAQ3 & LAQ4 & LAQ5 & LAQ6 \\
\hline Gen & 1 & $2427.26^{\star \star *}$ & 299.40 & 1087.06 & $11952.61^{* * *}$ & $35866.07^{* * *}$ & $4732.51^{* * *}$ \\
\hline OF & 2 & 106.96 & 300.65 & 791.15 & 1018.56 & $2766.80^{\star * *}$ & 406.21 \\
\hline PF & 2 & 19.22 & 40.72 & 231.39 & 2041.41 & 667.03 & 859.89 \\
\hline Gen*OF & 2 & 150.66 & 51.62 & 204.30 & 362.33 & 515.98 & 359.06 \\
\hline GenPF & 2 & 159.23 & 93.10 & 523.59 & $1421.15^{\star}$ & 598.15 & 755.79 \\
\hline OF*PF & 4 & 47.59 & $555.84^{*}$ & 411.20 & 1356.23 & 620.45 & 284.23 \\
\hline \multirow[t]{2}{*}{ Gen ${ }^{\star} \mathrm{OF}^{\star} \mathrm{PF}$} & 4 & 77.15 & $774.82^{\star *}$ & $1059.84^{* *}$ & 459.46 & $969.75^{*}$ & 559.33 \\
\hline & & SDQ1 & SDQ2 & SDQ3 & SDQ4 & SDQ5 & SDQ6 \\
\hline Gen & 1 & 0.50 & $2.28^{\star \star *}$ & $0.60^{*}$ & 0.01 & 0.17 & $7.41^{* *}$ \\
\hline OF & 2 & 0.23 & 0.08 & $0.58^{*}$ & $1.89^{*}$ & 23.06 & 2.44 \\
\hline PF & 2 & 0.39 & 0.04 & 0.12 & 0.11 & 7.41 & 0.51 \\
\hline Gen*OF & 2 & 0.25 & 0.02 & 0.12 & $1.12^{*}$ & 12.19 & 1.89 \\
\hline Gen*PF & 2 & 0.20 & 0.01 & 0.01 & 0.03 & 22.02 & 1.18 \\
\hline $\mathrm{OF}^{\star} \mathrm{PF}$ & 4 & 0.19 & 0.04 & 0.16 & 0.10 & 11.87 & 1.44 \\
\hline Gen*OF*PF & 4 & 0.17 & 0.05 & 0.07 & 0.14 & 16.97 & 0.61 \\
\hline
\end{tabular}

Table 2. The variation and mean comparison of the two cashew accessions with respect to the six quarterly intervals and the three levels of organic fertilizers.

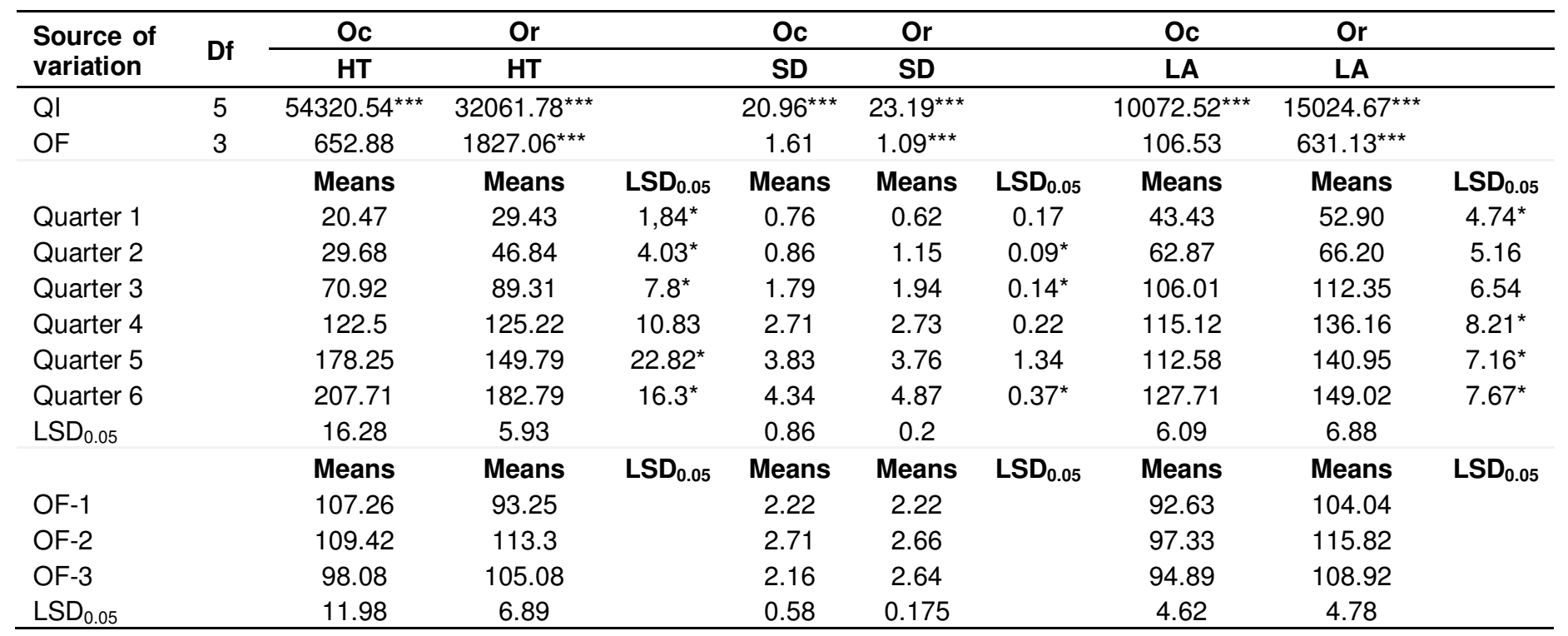

* DF, Degree of freedom; HT, plant height; SD, stem diameter; LA, leaf area; QI, quarterly interval; OF, organic fertilizer; OF-1, organic fertilizer (0level); OF-2, organic fertilizer (2.5 tons/ha); OF-3, organic fertilizer (5 tons/ha). 
Table 3. Broad sense heritability and measures of variability for three growth parameters measured for six quarterly intervals.

\begin{tabular}{cccc}
\hline Phenotypic traits & HB $(\%)$ & PCV $(\%)$ & GCV (\%) \\
\hline HTQ1 & 95.61 & 53.90 & 53.02 \\
HTQ2 & 93.06 & 84.40 & 82.66 \\
HTQ3 & 64.37 & 64.41 & 60.24 \\
HTQ4 & 2.30 & 22.04 & 20.23 \\
HTQ5 & 38.00 & 76.76 & 61.00 \\
HTQ6 & 52.83 & 59.00 & 50.50 \\
LAQ1 & 77.25 & 43.51 & 39.66 \\
LAQ2 & 13.03 & 18.52 & 7.77 \\
LAQ3 & 23.62 & 22.60 & 15.57 \\
LAQ4 & 62.67 & 58.44 & 55.22 \\
LAQ5 & 84.68 & 96.53 & 95.14 \\
LAQ6 & 56.61 & 37.07 & 32.78 \\
SDQ1 & 23.36 & 6.66 & 3.74 \\
SDQ2 & 88.58 & 8.88 & 8.58 \\
SDQ3 & 33.13 & 4.02 & 2.83 \\
SDQ4 & 0.27 & 2.90 & 1.23 \\
SDQ5 & 0.16 & 14.77 & 12.87 \\
SDQ6 & 45.14 & 8.19 & 6.85 \\
\hline
\end{tabular}

${ }^{*} \mathrm{HB}$, Broadsense heritability; PCV, phenotypic coefficient of variation; GCV, genotypic coefficient of variation; $\mathrm{HT}$, plant height measured for six (Q1 to $Q 6)$ quarterly intervals; LA, leaf area measured for six (Q1 to Q6) quarterly intervals; SD, stem diameter measured for six (Q1 to Q6) quarterly intervals.

Table 4. Trend analysis and the interaction of the six quarterly intervals and the three levels of organic fertilizer application on stem diameters.

\begin{tabular}{lccc}
\hline Sources of variation & df & SS & MS \\
\hline Quarterly Intervals & 5 & & $* \star *$ \\
Interval (Linear) & 1 & 1.243 & $1.243^{\star *}$ \\
Interval (Quadratic) & 1 & 0.111 & 0.111 \\
Interval (Cubic) & 1 & -0.052 & -0.052 \\
Interval (Quantic) & 1 & 0.0010 & 0.0010 \\
Interval (Quintic) & 1 & 0.345 & 0.345 \\
Organic fertilizer & 2 & & ${ }^{* *}$ \\
OF (Linear) & 1 & 0.536 & $0.536^{*}$ \\
OF (Quadratic) & 1 & -0.743 & $-0.743^{*}$ \\
Interval x OF & 10 & 2.718 & 0.2718 \\
Error & 34 & 6.368 & 0.187 \\
\hline
\end{tabular}

*df, Degree of freedom; Ss, sums of squares; MS, mean squares; OF, organic fertilizer.

every advancing quarters of growth measurements for the two accessions (Table 2). Conversely in Kas_Or, the response of the three growth parameters to the three levels of organic fertilizer was linearly inconsistent. The performance of plant height, leaf area and stem diameter in OF-2 (2.5 tonnes/ha) was significantly $(\mathrm{P} \leq 0.05)$ higher compared to OF-1 (the control) and OF-3 (5 tonnes/ha). The pair comparison of the two cashew accessions revealed significant $(P \leq 0.05)$ differences in the mean values of the six quarters for plant height except at the fourth quarter. Moreover, significant ( $P \leq$ $0.05)$ mean differences for the two accessions occurred only in quarters 2, 3 and 6 for stem diameter and in quarters 1, 4 and 6 for leaf area (Table 2). The only paired comparison of the accessions' means with significant $(P \leq 0.05)$ differences was observed for stem diameter in the third level of OF; in which Kas_Or had a higher stem diameter $(2.64 \mathrm{~cm})$ as against $2.16 \mathrm{~cm}$ in Kas_Oc (Table 2).

Broad sense heritability for the three growth traits was not consistent across the six quarters (Table 3 ). Very high $(>80 \%)$ broad sense heritability occurred for plant height (first and second quarter), leaf area (fifth quarter) and stem diameter (second quarter). From the same table, the PCV was generally higher than the GCV. Among the three traits, plant height showed higher CV (phenotypic and genotypic), although PCV and GCV for leaf area at the fifth quarter was the highest in this study (Table 3).

The six quarterly interval of growth measurement and the three levels of OF showed significant $(P \leq 0.05)$ trend analysis on stem diameter of the two cashew accessions (Table 4). Trend analysis of the interaction of these two factors on plant height and leaf area was not significant (Table not shown). The response of the two cashew accessions to varied intervals of growth measurement was consistently linear (Table 4 and Figure 1). Other forms of trend were not significant. The trend pattern of the response of the stem diameter to the three levels of OF was negatively quadratic (Table 4 and Figure 2). Linear relationship existed between two successive levels of OF for stem diameter; it was positively linear between 0 and 2.5 ton/ha OF and negatively linear between 2.5 and 5 ton/ha.

\section{DISCUSSION}

The remark of Philip and Unni (1984) that there exists extensive variability within the Anacardium occidentale L. is further shown in this study. The plant height, stem diameter and leaf area of the two accessions differed in their growth pattern, trend and response to the same nutritional conditions. The variation, among other reasons, could be due to the probable role of different environments in conditioning (through mutation) the genetic constitution of genotypes. Ochaja and Oro are within the same state in Nigeria. Despite the uniformity in the nut sizes of the two accessions from the two locations, significant variations existed between them for the studied phenotypic growth parameters. This may further attest to the fact that the assumption of uniformity within a mega-environment could be misleading in the evaluation of genetic materials (Gauch and Zobel, 1996; Yan and Kang, 2003). 


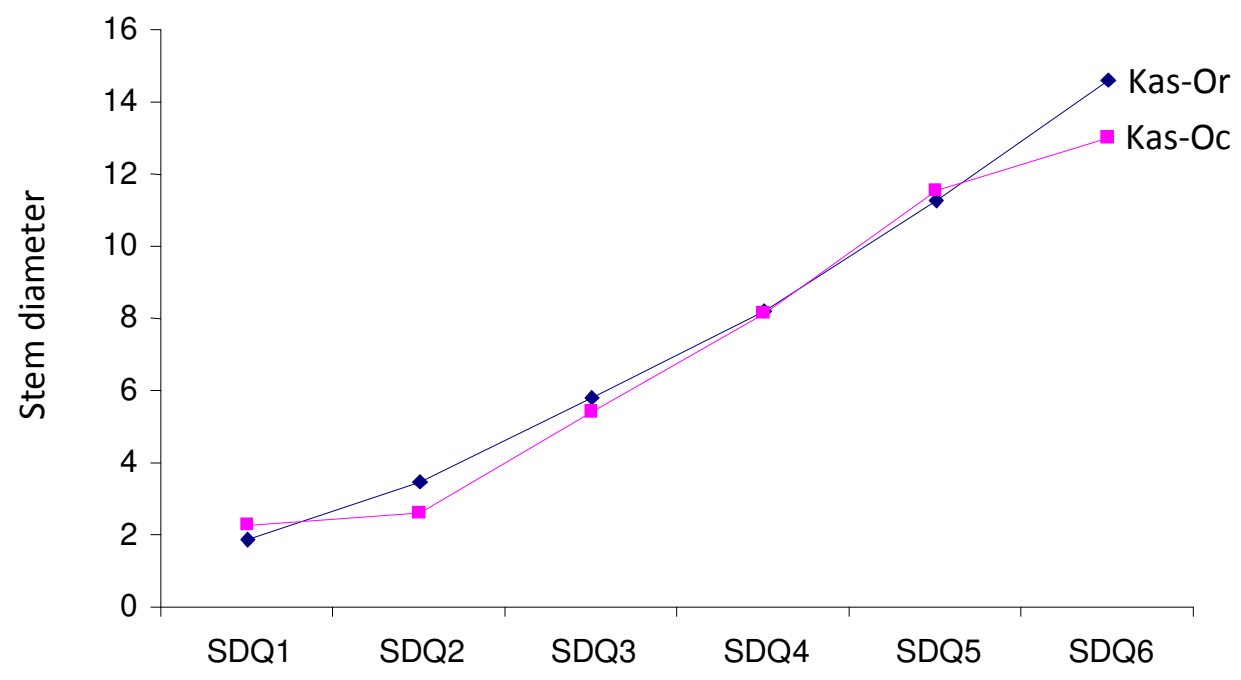

Six quarters of growth measurements

Figure 1. Linear response of the two cashew genotypes to six quarterly intervals measurements of the stem diameter.

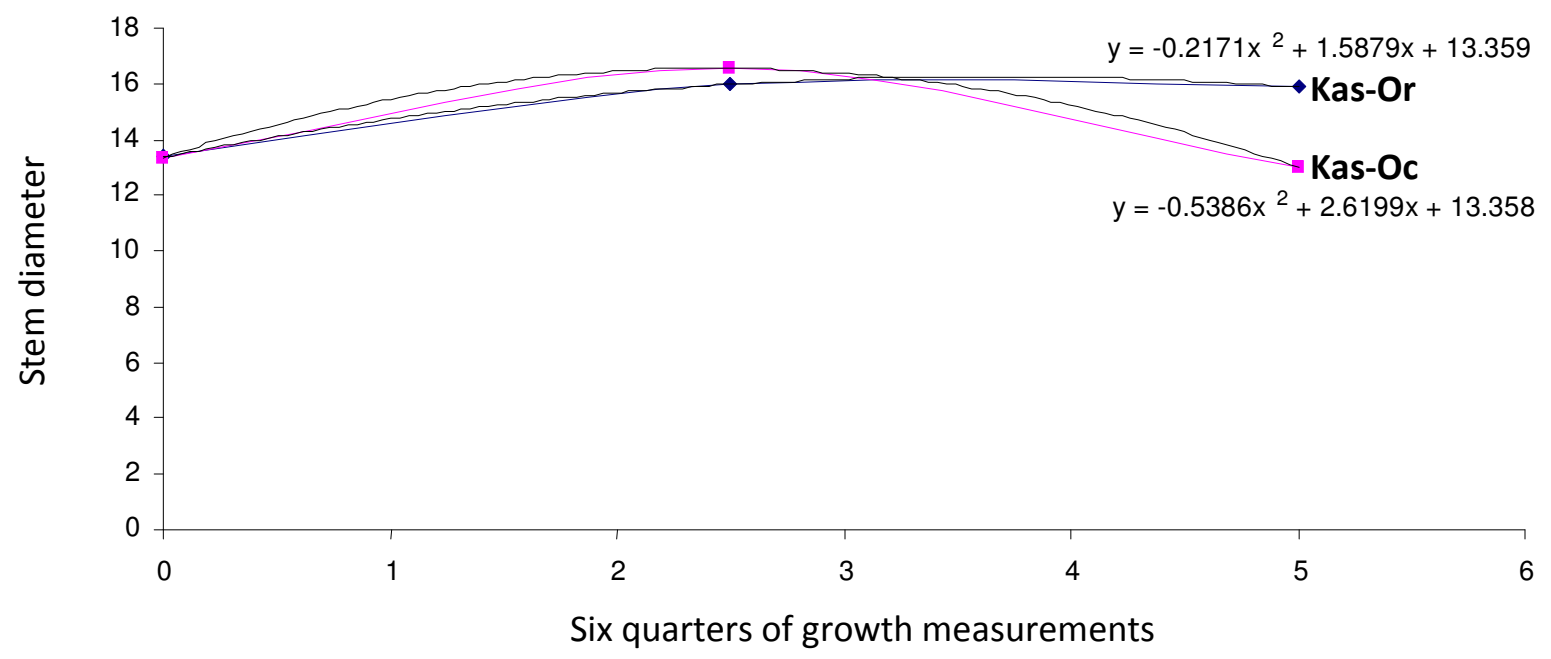

Figure 2. Negative quadratic response of the two Cashew genotypes to three levels of organic manure application.

Moreover, it was noteworthy that the allogamous reproductive system of cashew would remain a vital determinant of continuous genotypic and phenotypic variability among nuts generated on the same plant from various pollen sources. The result revealed differing levels of sensitivity of different accessions and timing of growth parameter measurements. This was in consonance to the result by Hammed et al. (2011) on the growth monitoring of cashew seedling for the three earlier months of field establishment and that of Vinod et al. (2010) for some Hevea brasiliensis seedlings. Just as growth was linearly continuous for three months as remarked by Hammed et al. (2011), growth equally advanced linearly (steadily, though with different magnitude of quantitative additions in the two accessions) for the two years of monitoring. This could be attributed to active cell division and elongation.

In this study, further increase of the tonnage of cocoa pod husk beyond 2.5 resulted in a declining trend in the growth of the stem diameter of cashew. Therefore, 2.5 tonnes/ha of cocoa pud husk would effectively and steadily facilitate linear increase in cashew stem diameter within the first twenty-four months of field establishment. This agrees to the findings by Opoku-Ameyaw and Appiah (2000), Bezerra et al. (2007), Hammed et al. (2011), Ibiremo et al. (2012) who reported that continuous 
nutrient addition to cashew varies with genotypes, age and the soil nutrient status.

The PCV and GCV are essential genetic parameter for the selection process of plant material. The result of higher PCV above GCV in this study conforms to the most popular occurrences in genetic studies (El-Hosary and Nawar, 1984; Abul-Naas et al., 1989; Kaushik et al., 2007; Adewale et al., 2010). However, the narrow differences between PCV and GCV and high heritability observed for some traits in this study indicate the importance of genetic variance in the inheritance of the studied characters. It would therefore be advisable that any selection for genotypes for any of these three traits should be done during the quarters when their phenotypic expression most linked to very high heritability.

\section{ACKNOWLEDGEMENT}

The authors wish to sincerely acknowledge the field and technical staff of the divisions of the Soils and Plant Nutrition and Crop Improvement of the Cocoa Research Institute of Nigeria, Ibadan for the generation of the data for this work

\section{REFERENCES}

Abul-Naas AA, Abdel-Barry AA, Rady S, El-Shawaf IS, El-Hosary AA (1989). Breeding studies in yield and its components in faba bean (Viciafaba L). Egypt Agron. 14:117-149.

Adavi RD (2008). Molecular diversity and phenotyping of selected cashew genotypes of Goa and physiological response of cv. GOA-1 to insitu moisture conservation. A PhD Thesis submitted to the University of Agricultural Sciences, Dharwad. p. 121.

Adewale BD, Kehinde OB, Popoola JO, Aremu CO (2010a). Seed metrics for genetic and shape determinations in African yam bean [Fabaceae] (Sphenostylis stenocarpa Hochst. Ex. A. Rich) Harms. Afr. J. Plant Sci. 4:107-115.

Adewale BD, Okonji C, Oyekanmi AA, Akintobi DAC, Aremu CO (2010). Genotypic variability and stability of some grain yield components of Cowpea. Afr. J. Agric. Res. 5:874-880.

Aliyu OM (2005).Application of tissue culture to cashew (AnacardiumoccidentaleL.) breeding: An appraisal. Afr. J. Biotech. 4:1485-1489.
Bezerra MA, de Lacerda CF, Filho EG, de Abreu CEB, Prisco JT (2007). Physiology of cashew plants grown under adverse conditions. Braz. J. Plant Physiol. 19:23-30.

El-Hosary AA, Nawar AA (1984).Gene effects in field beans (viciafaba L.) earliness and maturity. Egypt J. Genet. Cytol. 13:109-114.

Gauch HG, Zobel RW (1996). AMMI Analysis of yield trials. In: Kang MS, Gauch HG (eds.) Genotype-by-Environment Interaction. CRC Press., Boca Raton, Florida. pp. 85-122.

Gomez KA, Gomez AA (1984). Statistical procedures for agricultural Research. New York: John Wiley \& sons. p. 680

Hammed LA, Lawal BA, Kolapo KA (2011). Growth and nutrient uptake of cashew (Anacardium occidentale L.) Seedlings as affected by nutsize in the nursery. Afr. J. Agric. Res. 6:3962-3971

Ibiremo OS, Olubamiwa O, Agbeniyi SO, Akanbi OSO (2012). Response of cashew seedlings from different nut sizes to phosphate fertilizer and Arbuscularmycorrhizal inoculation in two soils in Nigeria. Int. J. Plant Anim. Environ. Sci. 2:147-158

Kaushik N, Kumar K, Kumar S, Kaushik N, Roy S (2007). Genetic variability and divergence studies in seed traits and oil content of Jatropha (Jatrophacurcas) accessions. Biomass Bioenergy 31:497502.

Ohler JG (1979). Cashew. Department of Agricultural Research, Royal Tropical Institute, Amsterdam, The Netherlands.

Opoku-Ameyaw K, Appiah MR (2000). Improving the growth of Cashew (Anacardium occidentale) seedlings interplanted into mature sheanut stands in Northern Ghana. Ghana J. Agric. Sci. 33:159-164

Phillip VJ, Unni PN (1984).In vitro propagation of cashew crop improvement. In: BhaskaraRao EVV, Khan HH (eds.); Cashew Research and Development CPCRI, Kasargod. pp. 77-82.

SAS Institute Inc. (2007). SAS OnlineDoc® 9.2. SAS Institute Inc., Cary,NC.

SasiVarma K (2002). Nutritional values of cashew nut. In: Singh HP, Balasubramanian PP, Venkatesh NH (eds) Indian Cashew Industry, Directorate of Cashew nut and Cocoa Development. pp. 124-129

Singh RK, Chaudhary BD (1985).Biometrical methods in quantitative genetic analysis. New Delhi: Kalyan Publishers. p. 318.

Soman CR (1997). Cashew kernel in human health. Cashew 11:7-11.

Vinod KK, Suryakumar M, Chandrasekhar TR, Nazeer MA (2010). Temporal stability of growth and yield among Hevea genotypes introduced to a non-traditional rubber growing region of peninsular India. Ann. For. Res. 53:107-115

Yan W, Kang MS (2003). GGE Biplot Analysis: A graphical tool for breeders, geneticists and Agronomists, CRC Press, Florida. p. 271. 